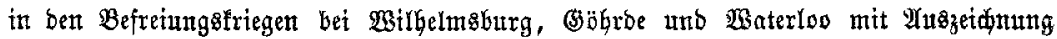

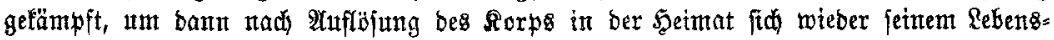
beruf zu wibmen.

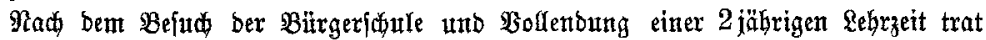
Ferbinand $\mathfrak{3 a r r m a n n}$ in bas Felbiägerforps zu Mintoen, futbierte bort von 1845

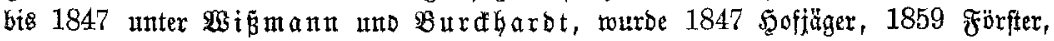

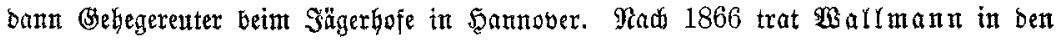

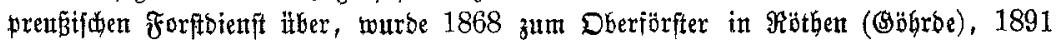

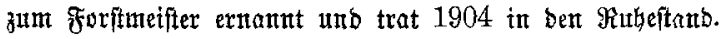

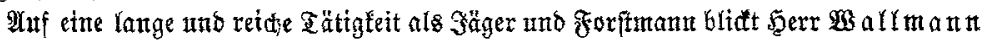

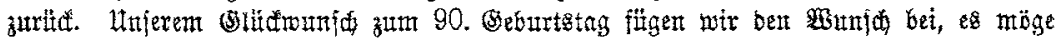
ifm befditeben fein, jeinen (seburt8tag now oft zu feiern wie ben 90 ten, in geiftigex Frifore unb bei vollex sefunbbeit.

\title{
V. Anzetigen.
}

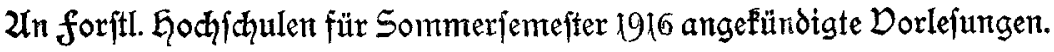 Utniverfität 2riünthen. \\ Beginn: 1. Mai.}

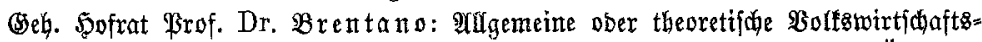

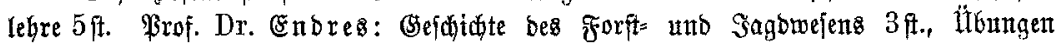

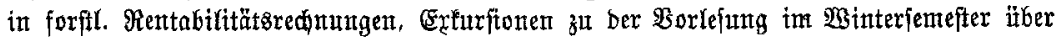

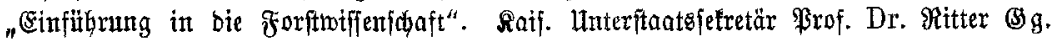

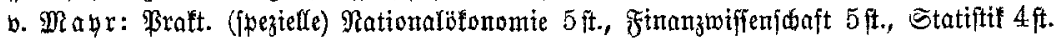

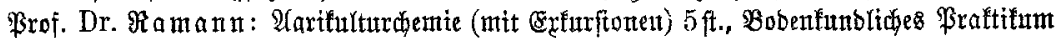

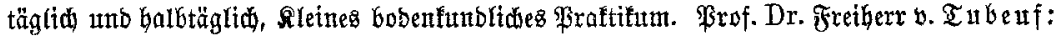
Bflanzenpathologie 5 ft., Speziflfe Botanil II. Teil: Naturgejditdte forflicher Rultur=

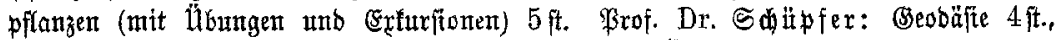

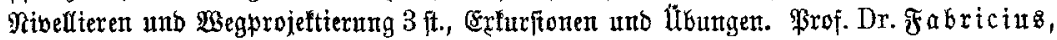
(

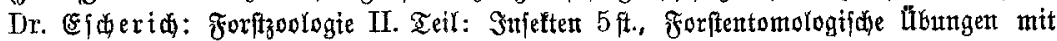

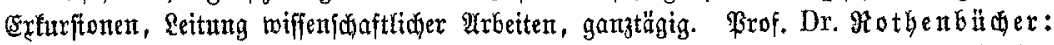

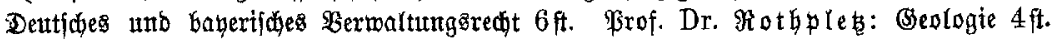
Brof. Dr. $\mathfrak{B}$ irlftätter; Drg. Experintentaldemie $5 \mathrm{ft}$. Brof. Dr. $5 e g t$ : Syftemattide Botanif 4 ft. Frivatbozent Dr. \&o

\section{Tedinifhe Godfihule zu Karlsruhe.}

Füter: Grunblebren ber büberen Mathematî̀. N. N.: Projeftionelehre mit

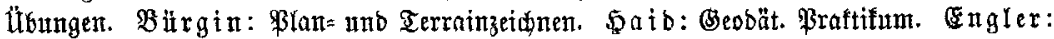

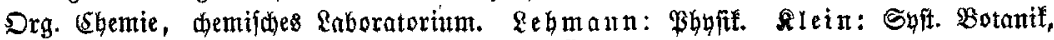

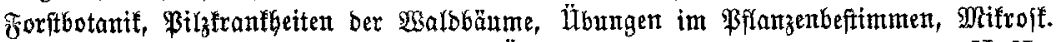

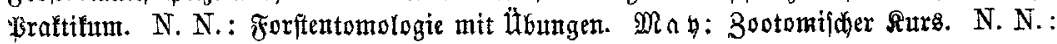
Geologte mit Fraftifum. Salbig: Bobenfunbe, Raboratorium. Siefert: Forftedino=

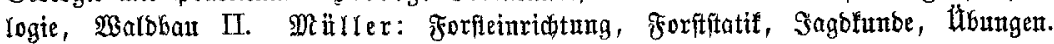

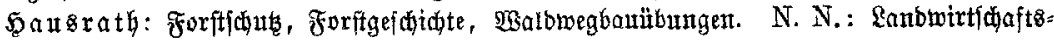

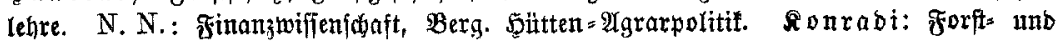
Эogbredt. 